\title{
Integrative Health and Healing Practices Specifically for Service Members: Self-Care Techniques
}

\author{
Richard P. Petri, Jr., MD, FAAPMR, FAAIM, COL MC, ${ }^{1, *}$ \\ Joan A.G. Walter, JD, PA, ${ }^{2}$ and Jon Wright ${ }^{3}$
}

\begin{abstract}
Background: There has been an ever-increasing utilization of integrative medicine (IM) by patients to manage their health. Dissatisfaction with depersonalized care is one of the significant factors causing patients to seek alternative means to meet their health care needs. These patients are often motivated to find care that coincides with their beliefs, values, and expectations. Medical health care systems must understand these concerns and work collaboratively with patients to achieve optimal outcomes and satisfaction levels. Self-care programs, when part of holistic treatment plans, are well-suited to address these concerns.

Objective: This article discusses the concepts of self-care, and active and passive participation, as well as briefly examining some IM modalities that can be used as self-care techniques.

Methods: This overview describes the history, concepts, uses, and relevant research of several IM modalities and their applications as self-care techniques. Recommendations for educational and clinical "next steps" are provided. Conclusions: IM self-care techniques can be incorporated effectively and safely into holistic treatment plans for North Atlantic Treaty Organization (NATO) Service members. Additional education, international collaboration, and research are necessary to improve the use of these techniques throughout the medical health care system.
\end{abstract}

Key Words: Self-Care, Patient-Centered, Integrative Medicine, Acupuncture, Acupressure, Meditation, Mindfulness, Exercise Movement Techniques, Spirituality, Religion, Martial Arts, Yoga, Reiki, Pranic Healing, Healing Touch

\section{INTRODUCTION}

I $\mathrm{N}$ THE PAST 20 YEARS, there has been increasing acceptance of complementary and alternative medicine (CAM) or integrative medicine (IM) for treating a growing number of conditions. Data show that $>50 \%$ of the Military popu- lation, including dependents, has used CAM interventions in recent years, and up to $66 \%$ of active-duty personnel use dietary supplements. ${ }^{1-6}$ Reviews of self-reporting population surveys suggest that Military personnel may be utilizing CAM services independent of conventional medical health services. ${ }^{7}$ Furthermore, the U.S. Military encourages

\footnotetext{
${ }^{1}$ United States Army, Chairman, NATO HFM-195 Task Force, Integrative Medicine Interventions for Military Personnel, El Paso, TX.

${ }^{2}$ Chief Operating Officer, Samueli Institute, Alexandria, VA.

${ }^{3}$ Summer Intern, Volunteer, Samueli Institute, Alexandria, VA.

This article was prepared as part of the work product of NATO Science and Technology Organization, Task Force, Human Factors and Medicine (STO-TR-HFM) 195, Integrative Medicine Interventions for Military Personnel.

*The opinions and assertions contained herein are the private views of the author and are not to be construed as official or as reflecting the views of the United States Army Medical Corps, the Army at large, or the Department of Defense. The author indicates that he does not have any conflicts of interests.
} 
individuals to take charge of their own health and to improve outcomes, while minimizing utilization of limited and costly services. ${ }^{8}$ Service members try to avoid prescription medications because of the side-effects and the potential negative impacts on Service members' lives and their careers, especially prescription medications used to treat pain and stress. Service members are utilizing an increasing number of IM modalities-such as prayer for one's own health, massage therapy, and relaxation techniques—often at out-of-pocket cost. ${ }^{4}$

Active-duty individuals may use IM either by prescription or, more frequently, without any medical supervision, to increase stamina, performance, and operational capacity; to alleviate chronic pain; or to cope with stress-related disorders. ${ }^{9,10}$

For the Military leadership and health care professionals in charge of this special population, it is critical to acquire a better knowledge of these IM interventions and the potential impact of the use of these modalities on Military medical services. Furthermore, it is imperative that health care providers know all the treatments their patients are utilizing. Patient and provider must work as a team to optimize the patient's care plan, expected outcomes, and levels of satisfaction.

\section{UNDERSTANDING IM FOR NATO FORCES ON THE LARGER STAGE}

North Atlantic Treaty Organization (NATO) forces are continuously deployed globally for various purposes, and medical care is a necessary component of those missions. Given that this care is provided in a multinational setting, it is crucial that medical personnel understand the systems used by each of the NATO participating countries; this is particularly true regarding IM practices, because these can vary widely from country to country. Important cultural, medical, and financial factors must be considered.

Individuals, as well as each nation's medical system, have diverse cultural expectations regarding necessary and appropriate care. Effective medical care is dependent upon having sensitivity to these differences. An IM modality may be considered standard care in one country while not being even recognized as a legitimate option in another country. NATO, as a multinational organization, can serve as a forum for an expansion of ideas and understanding among differing nations. Cooperative partnerships among countries as well as between allopathic (Western) and nonallopathic (Eastern) practitioners are imperative. National partnerships can set the foundation for this to occur, both within NATO as well as on the global stage. Multi-stakeholder education on the perspectives, potential benefits, limitations, and roles each system of care has to offer must be emphasized.

Often, health care "programs are primarily funded by government subsidies and administrated by a multi-tiered bureaucracy. Thus, any action undertaken in a public health program tends to be reactive, conservative and well-documented."11 Compounding this, increasing medical costs are having a deleterious effect on the sustainability of the system and resulting Military readiness. The addition of IM practices may provide cost-effective solutions to this problem. Improvements to the world's health care systems would benefit both the individual and the collective whole. The NATO Task Force can be a key to "opening the door" to achieve improved global health and healing.

\section{IM AS A PRACTICE FOR SELF-CARE: THE SHIFT TOWARD EMPOWERMENT}

Delivery of health care must be congruent with societal and individual beliefs and value systems to be effective. ${ }^{12,13}$ Otherwise, it is an oppressive and irrelevant system imposed upon its recipients. This is a basis for the concept of patient- or person-centered health care. ${ }^{14,15}$ Furthermore, to be effective, the care must be acceptable and easy to use for patients.

Many aspects of IM support the person-centered care model. These include (1) emphasis on individuality, (2) a holistic perspective (toward the individual as well as with respect to treatments), (3) empowerment of the patient, (4) a premise of self-healing, self-influencing, self-care, and self-awareness, (5) listening and partnerships, (6) exploring new models of disease, (7) illness, health and healing (energetics), (7) emphasis on healing and health rather than on symptom management or merely obtaining a cure, and (8) understanding the concept of "functional diseases" instead of disease-based diagnostic categories. ${ }^{16}$ This premise of the "body heals itself" goes beyond simply allowing a cut to heal or a cold to resolve without treatment, but rather, it is the inherent ability of each individual to affect how the body heals. How people perceive themselves and the degree to which they participate in this perception greatly affects the outcome. Thus, individuals need to participate in their own care, with guidance from the health care community, rather than having total reliance on practitionerdependent practices.

Self-care techniques provide a source of doing by patients instead of having something done to them. In the U.S. Army Surgeon General's Task Force report on pain management, IM modalities were described in terms of passive and active participation. ${ }^{17}$ Active participation is defined as the patient's active involvement in his or her own care by participating in both the care plan and treatment. An example of active participation is performing yoga for chronic low-back pain. In contrast to merely taking medication that might deliver analgesia, the patient practicing yoga takes an active step to adopt a new practice to heal the body in a truly empowering way, and is an active participant in the treatment delivery and lifestyle change. Conversely, in the passive-participation model, patients have treatment performed on them or medications prescribed to cure isolated symptoms with very minimal participation on the patients' part (swallowing a pill). The use of prescriptions is an example of providerbased care, which is largely passive therapy. Effective medical care can be optimized through the use of both active and 
passive participatory treatments. When the opportunity for active participation is available, it should be encouraged.

Use of active treatments leads to patient empowerment and personal responsibility for health and healing. In 2014, a Working Group (WG) led by the Samueli Institute performed a systematic review of Active self-care Complementary and Integrative Medicine therapies (ACT-CIM). One of the findings of the WG was that incorporating ACT-CIM into health care plans improves outcomes and quality of life; allows for more diverse, patient-centered treatment; promotes self-management; and is relatively safe and cost-effective. ${ }^{18}$

Patient participation, empowerment, and responsibility are as important in any health care system as technological, pharmaceutical, and surgical advancements.

It must be emphasized that the trend among Service members to seek treatment options beyond the care they are provided within the Military health care system does not necessarily imply a desire for active participation or patient empowerment. Rather, it should alert the medical community to potential problems and gaps within the existing system that lead patients to become dissatisfied with it and bypass it to achieve their goals. Moreover, Service members' motivations may include avoiding necessary care, pursuing fad regimens, or seeking drugs (pain management) or performance-enhancement (body-building supplements).

\section{ROLE OF SPECIFIC IM PRACTICES FOR NATO FORCES}

The discussion about self-care active techniques includes two types. First, there are techniques that require some certified-provider instruction to initiate treatment (e.g., acupressure), following which a patient may continue without provider assistance. The second type involves techniques that do not require provider certification but can be self-taught or performed with an assistive aid such as a digital versatile disc, compact disc, or other device (e.g., guided imagery). However, within this group of techniques, provider instruction could be beneficial (e.g., for yoga), as it may facilitate safe, effective use of the techniques, and lower the risk of injuries.

Several modalities are described briefly in the sections below, including relevant research as available. Each practice is either presented as an individual technique or in broad categories to enable ease of understanding this article, as some practices cross multiple categories. Finally, it must be emphasized that self-care should supplement or augment, not replace appropriate provider-based care.

\section{Acupuncture and Acupressure}

Acupuncture is an ancient Chinese healing technique in which the stimulation of specific points along meridian channels in the body is achieved by piercing the skin with needles in order to enhance the flow of energy, cure disease, relieve pain and stress, and regulate the body. Acupressure achieves the same health benefits through the application of pressure at the same acupuncture points, but without needle insertions. Both disciplines require education about the point locations and the benefit(s) of stimulating the specific points. Although, as comprehensive systems of care, both are practitioner-dependent modalities, simple acupressure regimens can be taught to patients as self-care treatments.

For example, the application of pressure to the area between the thumb and index finger (Fig. 1), known as Large Intestine 4 (LI 4), is often effective for treating headaches. Patients with migraine headaches could benefit from the practice of acupressure in the time periods between clinical appointments for maintenance and acute exacerbations. Use of acupressure as a self-care modality can be considered to be safe with minimal-to-no side-effects (as long as acupressure is avoided in areas of infections, fractures, lesions etc.) Current research on acupressure is limited; however, there are some compelling data on the benefits of acupuncture for pain relief. Research on acupuncture for neck and low-back pain has shown some clinically significantly short-term benefits, ranging from $26 \%-80 \%$ effectiveness. The data is encouraging for headaches as well. ${ }^{19-26}$

One effort, the Acupuncture Training Across Clinical Settings (ATACS) program, is a current initiative within the U.S. Department of Defense and Veterans Affairs. The goal of the initiative is to develop, pilot, evaluate, and implement a uniform tiered acupuncture education and training program for the health care providers of the Military Health System and Veterans Health Administration. The overarching goal is to increase capacity and access to standardized acupuncture treatments. ATACS programs train health care providers of various types, from medical aides to medical doctors, in Battlefield Acupuncture (BFA; refer to Chapter 5, pages 335-343) and provides for medical acupuncture training for a select group.

In 2010, the U.S. Army Surgeon General's Pain Management Task Force Report was published and used as the

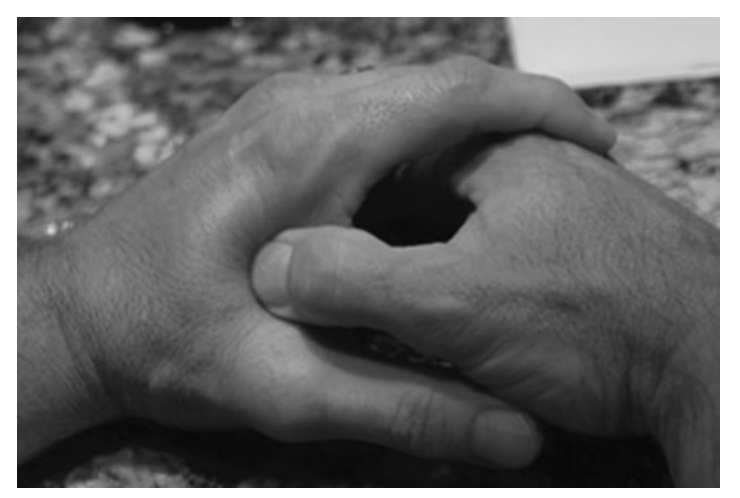

FIG. 1. Location of the LI 4 Acupressure Point often used for the treatment of headaches. Photograph by Richard Petri, Jr. (C) Photos by jocdoc. www.jocdoc.com 
basis for the Comprehensive Pain Management Campaign Plan (CPMCP). ${ }^{27}$ As a result of the CPMCP, Interdisciplinary Pain Management Centers (IPMCs) were developed at the Army's medical centers. These IPMCs are designed to provide a holistic pain-management approach, which includes acupuncture delivery by providers trained in BFA as well as by licensed (LAc) and medical acupuncturists.

Both the ATACS program and the IPMCs can serve as models for acupuncture implementation for NATO troops and beneficiaries, as experiential and outcomes data are gathered. An easy first step could be development of a cadre of BFA trainers who can educate and train individuals within the various NATO medical systems. Furthermore, education of individuals in simple acupressure regimens may provide patients with easy-to-use, quick, self-care treatments to address conditions such as pain, stress, and anxiety.

\section{Biofeedback}

Biofeedback is the technique of utilizing an individual's biologic/physiologic information or processes to alter those same processes. There are several types of biofeedback, based upon the types of information or processes that are being monitored. Brainwaves are monitored in electroencephalographic (ECG) biofeedback; electrocardiographic (EKG) biofeedback focuses on cardiovascular parameters, such as heart rate, blood pressure, and ECG/EKG data.

Biofeedback was first studied in animal models to evaluate involuntary responses and determine if animals could control those responses. This has since been expanded for use with humans. Most biofeedback is performed in specialized treatment centers or facilities. Positive modification of numerous conditions has been shown to occur with biofeedback. These include, but are not limited to, hyperarousal conditions, hypertension, ${ }^{28}$ headaches, ${ }^{29,30}$ and chronic pain. ${ }^{31}$

Recently, self-administered biofeedback techniques have become available for individuals. These require minimal instruction. The most simple of these is the use of thermal dots that sense changes in the temperature of the skin. Skin temperature is dependent upon blood flow through the capillaries. Cooler skin temperature reflects an increased level anxiety and stress, whereas warmer skin temperature reflects relaxation and calmness. The scientific reasoning behind this phenomenon is that as the body relaxes, the blood capillaries dilate, resulting in increased blood flow. This increased flow leads to increased surface temperature. (A 1960's fad that utilized this concept was mood rings.)

Another self-administered biofeedback technique is related to heart rate variability (HRV). The heart "pumping" is described as the heart rate (HR), which is typically expressed in beats per minute. The HR varies in response to many factors, such as physical activity. The beat-to-beat variability of the heart rate (HRV), which is affected by the information the heart receives from various inputs, is correlated with overall health. The autonomic nervous system controls the "fight-or- flight" response through the sympathetic and parasympathetic subsystems. The balance of these two systems affects the HRV. The HRV can be monitored with simple devices attached to a person's finger. Computerized programs assist patients to alter HRV through respiratory patterns and thought control, thereby inducing a relaxation response (RR), which optimizes HRV. ${ }^{32,33}$

Both of these self-administered techniques are typically used in conjunction with other IM techniques, such as meditation and imagery as part of self-care programs for stress management and pain control. Sophisticated computer programs have been developed that use "video games" in which the participants learns to evoke the RR by altering the "game." Simple game features include rising helium balloons, racing cars, and mountain skiing. More complicated games adjust the level of difficulty according to the degree of relaxation achieved.

\section{Energy Practices}

Energy medicine is an emerging field of science. Although people are aware of energy as the source that powers lights, computers, and just about everything in daily life, few people are aware of the energy fields that are detectable in living organisms. In this context, energy can refer to familiar and easily measurable frequencies of the electromagnetic spectrum such as light (including color) and sound. Energy may also refer to less-familiar influences of living systems for which measurement is currently more difficult.",34

Many energy-based practices and techniques, such as acupuncture, deal with these less-familiar subtle energies. Different cultures refer to this energy by different names. In Traditional Chinese Medicine it is known as Qi or chi, the "vital energy." In Japanese tradition, it is ki, "life energy." In the Indian culture, energy is referred to as prana, the Sanskrit word for life force. The basic principle of all energy practices is that disease is the result of an imbalance in the energy. Healing is achieved through balancing the energy, using the specific practice. ${ }^{34}$

Energy practices that can be used as self-care to balance energy in the body include Qigong, Reiki, therapeutic touch, and Pranic healing. All include practitioner- or media-based education to begin self-care programs.

Qigong combines movement with meditation for selfhealing or balancing of one's energy. Through practice, the individual develops an awareness of the body's energy and, through Qigong, can redirect and balance it. ${ }^{35}$

Reiki, Pranic healing, and therapeutic touch are examples of instructor- or practitioner-dependent modalities. That is, these treatments require a provider to treat the patient. While these modalities require the provider to have specialized training and certification in the entire array of techniques, the provider can educate the patient in simple, related self-care regimens to utilize between treatment sessions. In this way, 
the patient can be empowered through the instruction of simple, effective healing techniques.

\section{Herbal Medicine and Supplementation}

Individuals are using supplements and herbals at an everincreasing rate. ${ }^{36}$ In the United States alone, more than half of all health care consumers are estimated to have used herbs, herbal preparations, or natural-product supplements alone or with conventional medicines. ${ }^{37}$ Approximately $80 \%$ of the world's people use phytomedicine as their primary form of health care. ${ }^{37}$ Oftentimes, this use is not disclosed to providers, especially when the goals are weight reduction, increased physical and mental performance, or muscular development. Individuals often accept advice on what to take from friends rather than from reliable experts in the field.

Access to nutritional supplements and herbal products is available at grocery and specialty stores, on internet websites, and in underground markets. In most countries, prescriptions are not necessary for purchase and the industry is unregulated or minimally regulated. Research in the field is often limited and of poor quality. Therefore, there are safety concerns with purity, standardization, toxicity, interactions, side-effects, and legality. Approximately $75 \%$ of all conventional medicines are derived from living plants, ${ }^{37}$ as are herbal remedies, and it is not uncommon to find that "natural" remedies are adulterated with active drugs. ${ }^{38-40}$

The topics of dietary supplements and herbal remedies need to be addressed by a separate NATO Task Force, as these subjects are too large and complex for the CAM Task Force to address. Under a grant from Samueli Institute, funded by the U.S. Army Medical Research and Materiel Command, the RAND Corporation assembled an expert panel to discuss the regulation of dietary supplements in the Military in $2008 .^{2}$ Among the recommendations the panel produced were: the need to assess safety in the contexts within which supplements are being used; the need for evidence-based reviews of dietary supplements of particular safety concerns; and production and dissemination of educational materials to provide information on supplement safety. Medical communities need to begin honest dialogues with their patients regarding the significant use of supplements and herbals, the lack of adequate research on the risks and benefits of such use, and the impact of inappropriate use. International collaborations are necessary because countries are at varying stages with regard to knowledge databases and regulation.

\section{Meditative Practices (Mindfulness, Meditation, and Imagery)}

Meditative practice is a term for an expansive category of many techniques. All have a fundamental basis in the principle of directing one's awareness to the present. In life, it is impossible to avoid stress; therefore, the only control people have is the ability to change their perceptions of that stress when it comes and to find ways to cope with it.
Mindfulness allows a person to focus on the absolute present moment and away from a stressful event or other stressor. A popular analogy is looking up to the sky; rather than paying attention to the clouds, in mindfulness, the "attention" is focused on the blue space between the clouds, while acknowledging the existence of the clouds. An event or a stressor can be likened to a cloud. One can recognize that the stressor exists, but the attention does not need to remain with it. More importantly, one can learn not to attach oneself to the stressor cognitively or emotionally, which so often occurs. In doing so, less emphasis is placed on the event or stressor and more emphasis is focused on simple acknowledgement and "letting go." This results not only in a change of perspective but, as described by Benson in his landmark study on the RR, mindfulness also has a profound effect on physiologic and psychologic well-being. ${ }^{41}$

One of the misconceptions of meditation is that it is too difficult to practice. People often make excuses, such as "I just can't get it right," or "I can't relax." The aim of meditative practices is not to achieve some particular aim; rather, the goal is to train oneself to focus on the moment. Like many important behaviors, success at meditation improves with practice. Moreover, meditation can take on various forms, and each person's success at it is tied to the relevance of the form and acceptance of the particular behaviors it requires. For example, it takes all of one's focus on the present to bench press effectively and safely. Therefore, weight lifting can be a form of meditation for some people. When it is understood that many of the focused activities we engage in on a regular basis are really types of meditative practice, the impression that it takes years of practice and the skills of a yogi to appreciate the benefits of meditation (a potential stressor in itself) becomes less burdensome. The key message to patients is: "Just start."

Meditative practices can be used to ease numerous conditions. Pain and stress-related disorders including posttraumatic stress disorder and traumatic brain injury are especially pertinent areas for NATO populations. There is an abundance of web- and media-based resources available as assistive materials that enable self-care practices. Numerous organizations and corporations offer educational and practice materials. In addition, Militaries have developed their own programs related to meditative practices for their Service members and beneficiaries.

\section{Movement Practices (Exercise, Running, Yoga, T'ai Chi, and Martial Arts)}

Movement is fundamental to life. The human body is designed to move. In the words of Hippocrates,

all parts of the body which have a function, if used in moderation and exercised in labours in which each is accustomed, become thereby healthy, well developed and age more slowly, but if unused and left idle, they become liable to disease, defective in growth, and age quickly. ${ }^{42}$ 
Within Military systems, physical activity is a necessary part of training. Over the past decade, more activities that are regarded as IM modalities are being integrated into Military training programs. These include $t$ 'ai chi, Taekwondo, and jiujitsu, as well as mindfulness meditation and yoga. ${ }^{43-46}$ The "warrior" aspects of these practices make them more accepted by Service members.

Yoga is an ancient practice of linking mind, body and spirit through a combination of postures, breathing, and conscious relaxation and meditation. Derived from the Sanskrit word meaning, yoke, constellation, conjunction or union, yoga is the integration of physical, mental, and spiritual energies that enhance health and well-being. ${ }^{47}$ Yoga, as practiced in India, is truly a lifestyle composed of physical, spiritual, and nutritional aspects.

Yoga is not so widely accepted within the Military framework, in part, because of yoga's religious origins. Service members may be less willing to try an activeparticipation healing method that is strongly associated with differing religious views from their own views. To remedy this, the movements, poses, and exercises have been separated from the Eastern religious concepts and introduced under alternate names, such as "warrior breathing." This may increase the acceptance of yoga as being beneficial and consistent with promoting Military readiness, without the need to embrace a particular religious philosophy. In general, yoga in the West is seen more as one of many exercise programs, with numerous gyms, spas, and rehabilitation centers offering instructional classes.

Instruction in yoga can be provider- or media-based and then practiced as a self-care technique. The IPMCs within the U.S. Department of the Army offer yoga for treating pain conditions. The yoga taught at the IPMCs is primarily Hatha yoga. As initially developed, Hatha (force) yoga uses bodystrengthening and physical-purification techniques as means of self-transformation and transcendence and, ultimately, to clean and improve the condition of various physical organs.

All of the movement-oriented self-care techniques require provider instruction to learn proper techniques and forms. There is risk of injury if these are performed incorrectly or if there is a contraindication for the patient's condition. As an example, a person with a herniated disc should not perform forward flexing movements because of an increased risk of exacerbating or furthering the injury with forward flexion. Therefore, provider guidance is essential-both at the initiation of practice as well as through monitoring of the program.

Research on the benefits of exercise and movement programs is well-established ${ }^{48}$ and the World Health Organization embraces a global strategy "to promote and protect health through healthy eating and physical activity." 49 If performed properly, movement self-care programs offer benefits to cardiopulmonary, musculoskeletal, and immunologic systems as well as a heightened sense of well-being, increased overall quality of life (QoL), and improved human health and flourishing.

\section{Rituals, Spirituality, and Religiosity}

The areas of spirituality and religiosity can be provocative and controversial; however, there are sufficient data to suggest growing evidence for the correlation between religious and spiritual participation and health. ${ }^{50}$ In addition, data show a growing positive association between pain and prayer use for health concerns. ${ }^{51,52}$ Therefore, these areas warrant inclusion as self-care techniques.

Rituals are defined as enactments based on cultural beliefs and values. These can be social (celebration of a special event such as a birthday or national independence), Military (changing of command ceremonies), religious (prayer, mass), or spiritual (prayer, gratitude). ${ }^{53}$

Spirituality "refers to the transcendental relationship between a person and a higher being, a quality that goes beyond a specific religious affiliation." The word spirituality is derived from the Latin spiritus, which means breath, and is related to the Greek word pneuma, which refers to the vital spirit or soul. ${ }^{53}$ Spirituality is a complex and multidimensional construct, and can be defined as an open and individual experiential approach in the search for meaning and purpose in life ("content").

Religion is an institutional and culturally determined approach, which harnesses this essence and organizes the collective experiences of people (faith) into a closed system of beliefs and practices (form). ${ }^{54}$ The reader is referred to an article in this issue, entitled "Spirituality/Religiosity as a Resource for Coping in Soldiers: A Summary Report," pages 360-366, for a detailed discussion on these concepts.

Numerous research studies have shown prayer to be the most commonly used IM modality. ${ }^{4,55}$ Prayer has a profound effect on the healing process, even when no cure or improvement in the condition is likely. It has been explained this way:

[O]f course, we know that the faith factor is not a panaceathe mortality rate for human beings still remains $100 \%$. But even when physical healing does not occur, some degree of improvement almost always takes place, most often a sense of peace in facing a serious illness or disability. ${ }^{56}$

Other forms of spiritual and religious self-care techniques include experiencing gratitude, charitable works, forgiveness, hope, peacemaking, and compassion, to name a few. It is the responsibility of care providers to facilitate, provide, and utilize these "techniques" together with their patients. Compassion, for example, means to suffer with. According to Viktor Frankl, a psychiatrist who wrote of his experiences in Nazi concentration camps, "man is not destroyed by suffering; he is destroyed by suffering without meaning.",57

Care providers are responsible for helping their patients to find meaning and solace in the midst of their physical and mental pain and suffering; providers need to be more than just "someone in a white coat," issuing orders and prescribing pills. Despite the incomplete scientific evidence 
about how these techniques work, it is necessary that the medical communities understand and accept that patients utilize them as part of their own healing journeys. To minimize the use of these techniques and the impact of their use would be to minimize treatment plans as wholes and to fail to implement patient-centered care fully.

\section{DISCUSSION}

What is vital to the success of health care is the participation of the patient in treatment. This concept of active participation is one of the key aspects of the patient-centered care model. IM philosophy, concepts, and modalities emphasize this model of care as necessary for improved outcomes. Many IM modalities can be used as self-care techniques as part of comprehensive, holistic programs. This is not to advocate that patients should depend solely upon self-care techniques for their personal care, but rather that providers, patients, and communities need to collaborate to identify the best combinations of approaches to benefit patients. The end result would be a more effective, comprehensive health care system that is not always provider-dependent, but instead empowers patients to share responsibility for their own health.

\section{CONCLUSIONS}

Self-care practices offer patients autonomy over, empowerment regarding, and responsibility for their conditions. Many self-care techniques can be practiced safely and effectively after some provider- or media-based education. A self-care program must be incorporated into the overall health care treatment plan to maximize outcomes as well as the levels of satisfaction of providers and patients.

\section{RECOMMENDATIONS}

NATO is well-positioned to mediate the necessary and effective collaborations of multicountry initiatives because of the cultural diversity and knowledge of NATO's partners. The development of a self-care handbook for Service members and an educational handbook on the techniques for successful leadership could be a potential next step. Furthermore, the NATO Task Force on Integrative Medicine could be continued for the education about and implementation of best practices related to self-care. There needs to be consideration for international research on selfcare outcomes, patient QoL measures, and performance improvement (individually or collectively as a Military organization). Finally, in the areas of herbs and supplementation, a separate NATO Task Force should be established to review prevalence, usage patterns, risks, benefits, and regulatory considerations.

\section{AUTHOR DISCLOSURE STATEMENT}

COL Richard Petri, MC (MD), is an Active Duty Service Member in the United States Army and was appointed to the NATO panel HFM-195 ("Integrative Medicine Interventions for Military Personnel") as a technical team member. He was selected to the Chair of the panel in September 2013. Resources from the United States Army supported the travel expenses to the first four team meetings. The fifth meeting lodging expenses were partially supported by a grant from the Geneva Foundation. The remaining expenses were paid through personal resources. No competing financial conflicts exist. Joan Walter, PA, JD, is an executive at Samueli Institute, a health and wellness research non-profit organization, and a Principal Investigator of the DoD (United States Army) research grant to Samueli Institute, which funded some of the preliminary work of the NATO panel HFM-195. Resources from Samueli Institute were used to support the author's time and effort to write this chapter. No competing financial conflicts exist. Jon Wright was a summer volunteer at the Samueli Institute, a health and wellness research non-profit organization during the preparation of the manuscript. He is currently a student at the University of Virginia. Resources from Samueli Institute were not used to support the author's time and effort to assist in the development and editing of this chapter. No competing financial conflicts exist.

\section{REFERENCES}

1. Arsenault J, Kennedy J. Dietary supplement use in U.S. Army Special Operations candidates. Mil Med. 1999;164(7):495501.

2. Coulter ID, Newberry S, Hilton L. Regulation of Dietary Supplements in the Military. Santa Monica, CA: Rand Corporation Center for Military Health Policy Research Conference Proceedings; 2011:1-25.

3. George S, Jackson JL, Passamonti M. Complementary and alternative medicine in a military primary care clinic: A 5year cohort study. Mil Med. 2011;176(6):685-688.

4. Goertz C, Marriott BP, Finch MD, et al. Military report more complementary and alternative medicine use than civilians. $J$ Altern Complement Med. 2013;19(6):509-517.

5. Kent JB, Oh RC. Complementary and alternative medicine use among military family medicine patients in Hawaii. Mil Med. 2010;175(7):534-538.

6. White MR, Jacobson IG, Smith B, Wells TS, Gackstetter GD, Boyko EJ, Smith TC. Health care utilization among complementary and alternative medicine users in a large military cohort. BMC Complement Altern Med. 2011;11(27): $1-11$.

7. Davis MT, Mulvaney-Day N, Larson MJ, Hoover R, Mauch D. Complementary and alternative medicine among veterans and military personnel: A synthesis of population surveys. Med Care. 2014;52(12[suppl5]):S83-S90. 
8. Glavan KA, Haynes M, Jones DR, Philput C. A military application of a medical self-care program. Mil Med. 1998; 163(10):678-681.

9. Hammond MC, Vandenberg P. Complementary and Alternative Medicine. VA Healthcare, Department of Veterans Affairs; 2011. Online document at: www.research.va.gov/research_topics/ 2011cam_finalreport.pdf Accessed April 24, 2015.

10. Greenwood MRC, Oria M. Use of Dietary Supplements by Military Personnel. Washington, DC: National Academies Press; 2008. Online document at: www.nap.edu/catalog/ 12095.html Accessed July 18, 2015.

11. Giordano J, Garcia MK, Strickland G. Integrating Chinese traditional medicine into a U.S. public health paradigm. $J$ Altern Complement Med. 2004;10(4):706-710.

12. Jonas, W. Forward. In: Kelner M, Wellman B, Pescosolido B, Saks M. eds. Complementary and Alternative Medicine: Challenge and Change. New York, NY : Routledge, Taylor \& Francis; 2003: xi-xvi.

13. Balneaves L, Weeks L, Seely D. Patient decision making about complementary and alternative medicine in cancer management: Context and process. In Adams J, ed. Traditional, Complementary and Integrative Medicine: An International Reader. London, UK: Palgrave Macmillan; 2012: 71-78.

14. Epstein RM, Street RL Jr. The values and value of patientcentered care. Ann Fam Med. 2011;9(2):100-103.

15. Guyatt G, Montori V, Devereaux PJ, Schünemann H, Bhandari M. Patients at the center: In our practice, and in our use of language. ACP J Club. 2004;140(1):A11-A12.

16. Maizes V, Rakel D, Niemiec C. Integrative medicine and patient-centered care. Explore (N Y). 2009;5(5):277-289.

17. Pain Management Task Force Report. Office of the Army Surgeon General Pain Management Task Force Final Report May 2010. Online document at: www.regenesisbio.com/pdfs/ journal/pain_management_task_force_report.pdf Accessed May 7, 2014.

18. Delgado R, York A, Lee C, Crawford C, Buckenmaier C 3rd, Schoomaker E, Crawford P; Active Self-Care Therapies for Pain (PACT) Working Group. Assessing the quality, efficacy, and effectiveness of the current evidence base of active selfcare complementary and integrative medicine therapies for the management of chronic pain: A rapid evidence assessment of the literature. Pain Med. 2014;15(suppl1):S9-S20.

19. Freeman L. Acupuncture. In Freeman L. ed. Mosby's Complementary \& Alternative Medicine A Research-Based Approach, 2nd ed. St Louis, MO: Mosby; 2004:333-369.

20. Coeytaux RR, Kaufman JS, Kaptchuk TJ, Chen W, Miller WC, Callahan LF, Mann JD. A randomized, controlled trial of acupuncture for chronic daily headache. Headache. 2005;45(9): $1113-1123$.

21. Jena S, Witt CM, Brinkhaus B, Wegscheider K, Willich SN. Acupuncture in patients with headache. Cephalalgia. 2008; 28(9):969-979.

22. Thomas KJ, MacPherson H, Thorpe L, et al. Randomised controlled trial of a short course of traditional acupuncture compared with usual care for persistent non-specific low back pain. BMJ. 2006;333(7569):623.

23. Vickers AJ, Cronin AM, Maschino AC, et al; Acupuncture Trialists' Collaboration. Acupuncture for chronic pain: Individual patient data meta-analysis. Arch Intern Med. 2012;172(19):14441453.

24. White P, Lewith G, Prescott P, Conway J. Acupuncture versus placebo for the treatment of chronic mechanical neck pain: A randomized, controlled trial. Ann Intern Med. 2004;141(12): 911-919.

25. Witt CM, Jena S, Selim D, et al. Pragmatic randomized trial evaluating the clinical and economic effectiveness of acupuncture for chronic low back pain. Am J Epidemiol. 2006; 164(5):487-496.

26. Witt CM, Jena S, Brinkhaus B, Liecker B, Wegscheider K, Willich SN. Acupuncture for patients with chronic neck pain. Pain. 2006;125(1-2):98-106.

27. Arcand SA. Utilizing Integrative Medicine in the U.S. Army Medical Department: U.S. Army War College 2012. U.S. Army Medical Command. Operation Order (OPORD) 10-76 (USAMEDCOM Comprehensive Pain Management Campaign Plan). Washington, DC: Office of the Army Surgeon General; 2010.

28. Abgrall-Barbry G, Consoli SM. Psychological approaches in hypertension management. Presse Med. 2006;35(6[pt2]): 1088-1094.

29. Kanji N, White AR, Ernst E. Autogenic training for tension type headaches: A systematic review of controlled trials. Complement Ther Med. 2006;14(2):144-150.

30. Buse DC, Andrasik F. Behavioral medicine for migraine. Neurol Clin. 2009;27(2):445-465.

31. Jensen MP, Gertz KJ, Kupper AE, Braden AL, Howe JD, Hakimian S, Sherln LH. Steps toward developing an EEG biofeedback treatment for chronic pain Appl Psychophysiol Biofeedback. 2013;38(2):101-108.

32. Shaffer F, McCraty R, Zerr CL. A healthy heart is not a metronome: An integrative review of the heart's anatomy and heart rate variability. Front Psychol. 2014;5:1040.

33. Rajendra Acharya U, Paul Joseph K, Kannathal N, Lim CM, Suri JS. Heart rate variability: A review. Med Biol Eng Comput. 2006;44(12):1031-1051.

34. Energy Medicine. In: Trivieri L, et al. Alternative Medicine: The Definitive Guide, 2nd ed. Berkeley, CA: Celestial Arts; 2002:201-216.

35. Synovitz LB, Larson KL. Energy Medicine. In: Synovitz LB, Larson, KL. eds. Complementary and Alternative Medicine for Health Professionals: A Holistic Approach to Consumer Health. Burlington, MA: Jones \& Bartlett Learning; 2013:219-229.

36. Gahche J, Bailey R, Burt V, et al. Dietary supplement use among U.S. adults has increased since NHANES III (19881994). NCHS Data Brief. 2011;61:1-8.

37. Koopsen C, Young C. Integrative Nutrition. In Koopsen C, Young C. eds. Integrative Health: A Holistic Approach for Health Professionals. Sudbury, MA: Jones \& Bartlett Publishers; 2009;261-296.

38. Snyman T, Stewart MJ, Grove A, Steenkamp V. Adulteration of South African traditional herbal remedies. Ther Drug Monit. 2005;27(1):86-89.

39. Uttam G, Ferguson AM. Adulteration of herbal remedies with conventional drugs: Role of the clinical laboratory. In: Dasgupta A, Hammett-Stabler CA, eds. Herbal Supplements: Efficacy, Toxicity, Interactions with Western Drugs, and Effects on Clinical Laboratory Tests. Hoboken, NJ: John Wiley \& Sons; 2011:369-386. 
40. Newmaster SG, Grguric M, Shanmughanandhan D, Ramalingam S, Ragupathy S. DNA barcoding detects contamination and substitution in North American herbal products. BMC Med. 2013;11:222.

41. Benson $\mathrm{H}$. The relaxation response: History, physiological basis and clinical usefulness. Acta Med Scand Suppl. 1982; 660:231-237.

42. Freeman L. Exercise as an Alternative Therapy. In Freeman L. ed. Mosby's Complementary \& Alternative Medicine A Research-Based Approach, 2nd ed. St Louis, MO: Mosby; 2004:481-516.

43. Culotti PC. Tai Chi Training for Veterans. Online document at: taichihealth.com/?page_id=1033 Accessed July 6, 2015.

44. Lynch V. Tai Chi Classes Offered to Build Resiliency, Help Prevent Suicide. The Official Homepage of the United States Army. Online document at: www.army.mil/article/45441/ Tai_Chi_classes_offered_to_build_resiliency_help_prevent_ suicide/ Accessed July 6, 2015.

45. Club Jiu-Jitsu, Virginia Medical Institute. Jiu-Jitsu Club. Online document at: www.vmi.edu/Content.aspx?id=10737 419467 Accessed July 6, 2015.

46. Dong-kyun H. U.S. Soldiers Train at World Tae Kwon Do Headquarters. The Official Homepage of the United States Army. Online document at: www.army.mil/article/90372/ U_S_Soldiers_train_at_World_Tae_Kwon_Do_headquarters/ Accessed July 6, 2015.

47. Koopsen C, Young C. Healing Effects of Physical Activity and Movement. In Koopsen $\mathrm{C}$, Young $\mathrm{C}$. eds. Integrative Health: A Holistic Approach for Health Professionals. Sudbury, MA: Jones \& Bartlett Publishers; 2009;317-341.

48. Vina J, Sanchis-Gomar F, Martinez-Bello V, Gomez-Cabrera MC. Exercise acts as a drug; the pharmacological benefits of exercise. Br J Pharmacol. 2012;167(1):1-12.

49. World Health Organization Global Strategy on Diet, Physical Activity and Health. Global Strategy on Diet, Physical Activity and Health. Online document at: www.who.int/ dietphysicalactivity/goals/en/ Accessed July 6, 2015.
50. Schlitz M. Meditation, prayer and spiritual healing: The evidence. Perm J. 2005;9(3):63-66.

51. Wachholtz A, Sambamoorthi U. National trends in prayer use as a coping mechanism for health concerns: Changes from 2002 to 2007. Psychol Relig Spiritual. 2011;3(2):67-77.

52. Kirmayer LJ. The cultural diversity of healing: Meaning, metaphor, and mechanism. Heart Views. 2013;14(1):39-40.

53. Koopsen C, Young C. Health and the Human Spirit. In Koopsen C, Young C. eds. Integrative Health: A Holistic Approach for Health Professionals. Sudbury, MA: Jones \& Bartlett Publishers; 2009; 31-57.

54. Büssing A. Measures of spirituality in health care. In: Cobb MR, Puchalski CM, Rumbold B, eds. Oxford Textbook of Spirituality in Healthcare. Oxford, UK: Oxford University Press; 2012:323-331.

55. Prayer and Spirituality in Health: Ancient Practices, Modern Science. CAM at the NIH: Focus on Complementary and Alternative Medicine. 2005:XII(1):1-4. Online document at: www.jpsych.com/pdfs/NCCAM\%20-\%20Prayer\%20and\%20 Spirituality\%20in\%20Health.pdf Accessed July 6, 2015.

56. Matthew DA, Clark C. Healing the Body: Restoring Our Physical Selves. In: Matthew DA, Clark C. eds. The Faith Factor: Proof of the Healing Power of Prayer. New York, NY: Penguin Books;1996: 60-82.

57. Frankl VE. Man's Search for Meaning. New York: Simon \& Schuster; 1959.

Address correspondence to: Richard P. Petri, Jr., MD, FAAPMR, FAAIM, COL MC United States Army Chairman, NATO HFM-195 Task Force

Integrative Medicine Interventions for Military Personnel 5005 North Piedras Street El Paso, TX 79920

E-mail: richard.p.petri.mil@mail.mil; richard@petrijr.com 